\title{
Futility in Transcatheter Aortic Valve Implantation: A Search for Clarity
}

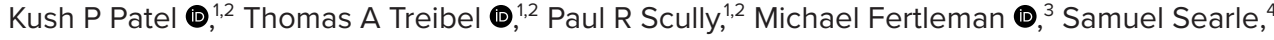 \\ Daniel Davis (1), James C Moon (1,2 and Michael J Mullen ${ }^{1,2}$
}

\begin{abstract}
1. Institute of Cardiovascular Sciences, University College London, London, UK; 2. Barts Heart Centre, St Bartholomew's Hospital, London, UK;
3. Cutrale Perioperative and Ageing Group, Department of Bioengineering, Imperial College London, London, UK; 4. MRC Unit for Lifelong

Health and Ageing, University College London, London, UK
\end{abstract}

\begin{abstract}
Although transcatheter aortic valve implantation (TAVI) has revolutionised the landscape of treatment for aortic stenosis, there exists a cohort of patients where TAVI is deemed futile. Among the pivotal high-risk trials, one-third to half of patients either died or received no symptomatic benefit from the procedure at 1 year. Futility of TAVI results in the unnecessary exposure of risk for patients and inefficient resource utilisation for healthcare services. Several cardiac and extra-cardiac conditions and frailty increase the risk of mortality despite TAVI. Among the survivors, these comorbidities can inhibit improvements in symptoms and quality of life. However, certain conditions are reversible with TAVI (e.g. functional mitral regurgitation), attenuating the risk and improving outcomes. Quantification of disease severity, identification of reversible factors and a systematic evaluation of frailty can substantially improve risk stratification and outcomes. This review examines the contribution of pre-existing comorbidities towards futility in TAVI and suggests a systematic approach to guide patient evaluation.
\end{abstract}

\section{Keywords}

Transcatheter aortic valve implantation, aortic stenosis, futility, risk stratification, resource utilisation, frailty, multimorbidity

Disclosure: KPP and PRS are supported by a clinical research training fellowship from the British Heart Foundation. KPP has received a project grant from Edwards Lifesciences. TAT is supported by a BHF Intermediate Research Fellowship (FS/19/35/34374). JCM is directly and indirectly supported by the UCLH NIHR Biomedical Research Centre and Biomedical Research Unit at UCLH and Barts, respectively. MM has received grants and personal fees from Edwards Lifesciences, and personal fees from Abbott Vascular.

Received: 25 May 2021 Accepted: 5 October 2021 Citation: Interventional Cardiology 2022;17:e01. DOI: https://doi.org/10.15420/icr.2021.15

Correspondence: Michael J Mullen, Barts Heart Centre, St Bartholomew's Hospital, West Smithfield, London EC1A 7BE, UK. E: mmullen@nhs.net

Open Access: This work is open access under the CC-BY-NC 4.0 License which allows users to copy, redistribute and make derivative works for non-commercial purposes, provided the original work is cited correctly.

Transcatheter aortic valve implantation (TAVI) has improved outcomes for many patients with aortic stenosis (AS), including high-risk and inoperable patients. However, some patients either have a high mortality despite TAVI or receive no symptomatic/functional benefit from the procedure. In the CoreValve US Pivotal Extreme and High Risk trials, TAVI was futile at 1 year in $50.8 \%$ of patients; $30.2 \%$ had died; quality of life (QoL) did not improve in 19.6\%, and declined in 1.0\%.' Similarly, the PARTNER high-risk trial, showed that TAVI was futile in $40 \%$ of patients. ${ }^{2}$ Although technological, operator and pathway improvements have reduced mortality and complications since its inception, TAVI remains expensive, invasive and carries risk. ${ }^{3} \mathrm{TAVI}$ studies have primarily focused on identifying predictors of mortality and major adverse cardiovascular events; however, many elderly TAVI patients value different treatment goals, such as independence and QoL.

Current guidelines define futility as a lack of survival or improvement in QoL/symptoms at 1year post-TAVI and do not recommend intervention for AS if TAVI is deemed futile. ${ }^{4}$ Although predicting outcomes and making management decisions can be challenging, it is becoming increasingly important as the utility of TAVI expands.

This review aims to provide clarity on the topic by discussing the decisions regarding futility, evaluating the impact of comorbidities on both mortality and functional outcomes, and importantly, which comorbidities can improve following TAVI. Although not exhaustive, the comorbidities discussed here represent those that are relevant and most influential in a high-risk/inoperable population with severe symptomatic AS. Asymptomatic patients are not discussed in this review, but may benefit from TAVI, largely from reducing the risk of mortality from AS and associated comorbidities

\section{Methods}

PubMed was searched for articles relating to TAVI in high-risk and prohibitive-risk patients with severe symptomatic AS between 2010 and 2020. The following free-text terms were used to identify relevant references: predictors of outcomes, mortality, functional outcomes, symptomatic changes and futility. Articles were screened for their relevance to the topic and excluded if they were not relevant, were duplicates or not in English. Additional references were identified by searching reference lists of included articles and guidelines. Comorbidities were then selected based on their relative impact on futility, consistency in the literature, and both their relevance and prevalence in the high-risk/surgically inoperable TAVI population. This was discussed and decided upon by all authors. The quality of each reference was checked by two authors (KPP and MJM). All authors were involved in providing expert opinion to interpret the data and formulate recommendations. 
This review article discusses comorbidities associated with futility in TAVI and those that can improve with TAVI. It then focuses on patient evaluation, challenges in grading the severity of AS and symptom assessment. Finally, it brings together all these elements into validated risk stratification tools, discussing their merits and limitations, before describing the pivotal role played by the multidisciplinary team.

\section{Cardiac Conditions Affecting TAVI Outcomes AF}

Although AF is a marker of increased morbidity, it has been shown to independently predict mortality at 1 year (HR compared with sinus rhythm $1.88-2.36)$, but not at 30 days. ${ }^{5-7}$ Mortality is often related to heart failure; however, renal failure, thromboembolic disease and mitral regurgitation are all associated with AF, and are likely to contribute to mortality. ${ }^{8,9}$ The risk increases with higher heart rate and $\mathrm{CHA}_{2} \mathrm{DS}_{2}$ VASc scores, supporting the importance of rate-control and comorbidities in determining futility. ${ }^{5,6}$ Stroke post-TAVI is an important determinant of functionality and quality of life. Pre-TAVI AF has not been shown to increase the risk of stroke, whereas new AF post-TAVI does. ${ }^{7}$ This is likely to be due to differences in antithrombotic treatment.10

\section{Left Ventricular Function and Structure}

Left ventricular systolic dysfunction independently increases mortality from heart failure and sudden cardiac death post-TAVI, with worse function conferring a higher risk." However, low transvalvular flow (measured as indexed stroke volume $\leq 35 \mathrm{ml} / \mathrm{m}^{2}$ ) may be a better prognostic marker than left ventricular ejection fraction (LVEF). This is supported by poorer outcomes in patients with paradoxical low-flow, low-gradient (LFLG) aortic stenosis (AS; where LVEF is normal) and a study where low flow remained an independent predictor of mortality (HR 1.29; 95\% Cl [1.03-1.62]), but LVEF and mean gradient did not.12 Thus, the effect of low forward flow might be more important than the mechanism causing it. It should be noted that despite poor outcomes compared with normal-flow, highgradient patients, those with LFLG have a lower mortality with TAVI than with conservative treatment ( $\mathrm{HR} 0.36 ; 95 \% \mathrm{Cl}$ [0.24-0.55]; $p<0.001) .{ }^{13}$ This is the case for both classical LFLG AS (HR 0.43; 95\% Cl [0.19-0.98]; $p=0.04$ ) and paradoxical LFLG AS (HR 0.38; 95\% Cl [0.16-0.87]; $p=0.02){ }^{14}$ Among survivors, functional outcomes at 1 year post-TAVI with low flow are comparable to normal flow patients. ${ }^{12}$

Left ventricular systolic dysfunction can also be reversible in AS patients, with improvements seen in up to two-thirds of patients as early as 48 hours post-TAVI and continued up to over 1 year post-TAVI. Determinants of improvement in left ventricular systolic dysfunction are high transvalvular gradient at baseline and the absence of a permanent pacemaker. ${ }^{15}$

Even among patients with preserved LVEF, further refinement of risk is beneficial. Strain imaging is a more sensitive marker of LV systolic function than LVEF. Studies have demonstrated among patients with preserved LVEF, Iongitudinal strain can predict mortality over and above traditional risk factors (for every $1 \%$ increase in longitudinal strain HR 1.05-1.42; $p<0.0001) .{ }^{16,17}$ A marked impact on mortality was observed in patients with longitudinal strain $<-12.1 \%$ compared with better strain values $(10 \%$ had died at 1 year)..$^{17}$

Cardiac fibrosis, which can either be reversible interstitial fibrosis or irreversible replacement fibrosis, develops as part of the remodelling process in AS, and in the case of replacement fibrosis, can be associated with previous MI. Replacement fibrosis, particularly in the mid-wall, identified using late gadolinium enhancement on cardiac MRI, independently predicts mortality (HR 5.35; 95\% Cl [1.16-24.56]). ${ }^{18}$ It also precludes favourable reverse remodelling post-TAVI, but does not affect changes in LVEF.19 Extracellular volume measured using cardiac MRI, is a surrogate marker for diffuse fibrosis. Bearing in mind the constituents of extracellular space, one study demonstrated it independently predicts mortality after aortic valve replacement at a median of 3.8 years (HR per percentage increase in extracellular volume percentage: 1.10; $95 \% \mathrm{Cl}$ [1.02-1.19]). The study demonstrated 52.7 deaths per 1,000 patient years with an extracellular volume percentage $>29.1 \%{ }^{20}$

Transthyretin amyloidosis (ATTR) has been identified as a common comorbidity in TAVI patients (13-16\%). ${ }^{21,22}$ TAVI has been shown to improve outcomes among patients with coexisting AS and ATTR compared with medical therapy $(p=0.03)$. Compared with patients with only AS, patients with AS and ATTR had a similar mortality ( $23 \%$ versus $21 \%$; $p=0.71)$ and procedural complications were similar $(p=0.77) .{ }^{21}$ Prospective studies are required to ascertain functional outcomes and reverse remodelling in patients with coexisting AS and ATTR.

Left ventricular function, mitral regurgitation (MR), pulmonary hypertension $(\mathrm{PH})$ and right ventricular dysfunction (RVD) are inextricably linked, such that each pathology influences the others. Therefore, teasing out the contribution of individual diseases to outcomes is challenging, creating controversy among studies.

\section{Mitral Regurgitation, Pulmonary Hypertension and Right Ventricular Dysfunction}

MR independently increases mortality at both 30 days (effect size $-0.18 ; 95 \%$ [Cl 0.31, -0.04$]$ ) and 1 year (effect size $-0.22,95 \% \mathrm{Cl}[-0.36$, $-0.08]$ ). ${ }^{23}$ Despite this, TAVI in patients with $\geq$ moderate MR remains better than medical therapy for improving mortality at 1 year ( $\mathrm{HR} 0.38 ; 95 \% \mathrm{Cl}$ [0.019-0.75]). ${ }^{24} \mathrm{TAVI}$ can also reduce MR; patients with functional MR, and the absence of severe pulmonary hypertension, AF and coronary artery disease increased the likelihood of such an improvement. ${ }^{25,26}$ Between $51 \%$ and $58 \%$ of patients with moderate/severe functional MR at baseline experience at least one or more grade improvement in MR at 1 year. ${ }^{26-28}$

Another observational study demonstrated moderate/severe MR improved in $79 \%$ of patients with functional aetiology compared with $50 \%$ of those with primary aetiology $(p=0.025) .{ }^{25}$ Interestingly, among patients where $\geq M R$ persists post-TAVI, left ventricular reverse remodelling, improvement in symptoms and New York Heat Association functional class do not seem to be adversely affected. ${ }^{29}$ This suggests that the risk of futility with TAVI increases with primary MR and the presence of associated comorbidities. With advances in transcatheter techniques, patients in whom TAVI does not reduce MR, transcatheter mitral valve repair/replacement can be an option; with initial studies demonstrating high procedural success, an acceptable safety profile and an improvement in symptoms. ${ }^{30,31}$ However, as we have learned from the COAPT and MITRA-FR studies, patient selection is key to achieving benefit. ${ }^{32}$

MR pre- or post-TAVI increases left atrial volume and pressure that eventually can result in $\mathrm{PH}$. A meta-analysis of TAVI patients demonstrated that $\mathrm{PH}$ (defined as pulmonary artery systolic pressure $>60 \mathrm{mmHg}$ ) increased the risk of all-cause mortality both at 30 days (OR 1.48; 95\% $\mathrm{Cl}$ [1.17-1.88]) and at 1 year (OR 1.39; 95\% Cl [1.24-1.57]), along with acute kidney injury at 30 days and stroke at 1 year. ${ }^{33}$ Pre-capillary and combined $\mathrm{PH}$, and increasing severity of $\mathrm{PH}$ confer a higher risk of mortality. ${ }^{34,35}$ Persistence of $\mathrm{PH}$, regardless of its aetiology, seems to be more important than baseline $\mathrm{PH}$ in predicting outcomes. Approximately half of patients 
with $\mathrm{PH}$ have immediate improvement in pulmonary artery systolic pressure post-TAVI, which is sustained up to a year. ${ }^{36}$ This improvement is more likely with a LVEF $>40 \%$, functional MR, mild diastolic dysfunction and in the absence of moderate to severe TR and $\mathrm{AF}^{36,37}$

By comparison, PH caused by chronic lung disease or associated with pulmonary vascular remodelling is less likely to improve with TAVI. ${ }^{34}$ Functional class improves regardless of baseline $\mathrm{PH}$, again suggesting that if AS is the dominant pathology, patients are likely to benefit from TAVI. $^{38}$ Therefore, among patients with $\mathrm{PH}$, the risk of futility increases with the severity of $\mathrm{PH}$, associated comorbidities and non-AS related aetiology of $\mathrm{PH}$.

RVD is often the consequence of transmitted pressure from the AS-loaded left ventricle, but co-existing pulmonary disease and other causes of precapillary PH do contribute. RVD (defined as tricuspid annular plane systolic excursion $<1.7 \mathrm{~cm}$ ) is prognostically important (HR at 12 and 43 months for all-cause mortality 2.94; 95\% Cl [2.02-4.27] and 2.14; $95 \% \mathrm{Cl}$ [1.31-3.51]; $p<0.001$, respectively). ${ }^{39.40}$ Over half of patients with baseline RVD demonstrate RV functional recovery within days post-TAVI, which is likely to be due to the reduction in LV afterload. Among patients in whom RVD did not recover, mortality (particularly early mortality) is up to eightfold higher. AF and a lower LVEF reduce the chances of recovery. ${ }^{39}$ Further work is required to determine the extent of symptomatic benefit that patients with RVD derive.

\section{Extra-cardiac Conditions Affecting TAVI Outcomes Anaemia}

Anaemia is associated with a poorer prognosis in a severity-dependant manner and affects mortality at 1 year (haemoglobin $<10 \mathrm{~g} / \mathrm{dl}$, HR 2.78; $95 \% \mathrm{Cl}$ [1.60-4.82]; haemoglobin $<13 \mathrm{~g} / \mathrm{dl}$ for men and $<12 \mathrm{~g} / \mathrm{dl}$ for women, HR 2.10; 95\% C: [1.06-4.18]) rather than at 30 days, and increases rates of hospitalisation due to heart failure. ${ }^{41-44}$ However, TAVI can also lead to the resolution of pre-existing anaemia; particularly that caused by ASinduced intravascular haemolysis and Von Willebrand factor cleavage. ${ }^{45}$ Post-TAVI anaemia rather than baseline anaemia is predictive of a poor symptomatic response to TAVI, indicating that non-AS-related causes of anaemia (such as renal failure) that persist post-TAVI are likely to affect outcomes, including symptom improvement. ${ }^{46}$ Targeting a treatable cause of anaemia in AS patients; for example with iron therapy, needs to be evaluated in prospective studies.

\section{Chronic Lung Disease}

Both chronic obstructive pulmonary disease (COPD) and restrictive lung disease increase the risk of mortality, in the short and long term (HR for 1-year all-cause mortality for COPD 1.09-1.46, 95\% Cl [1.02-1.79]; HR for restrictive lung disease $2.25,95 \% \mathrm{Cl}[1.35-3.75]) .{ }^{47,48}$ Poor exercise tolerance measured using a 6-minute walk test (6MWT), oxygen dependency and the use of non-invasive ventilation are recognised predictors of TAVI futility. ${ }^{48,49}$ These factors all indicate a higher severity of lung disease. Consequently, patients with CLD stand to gain less of an improvement in New York Heat Association status with TAVI, although up to $80 \%$ of them can experience some improvement. ${ }^{49,50}$ The rate of futility among TAVI patients with CLD can be as high as $57 \%$ at 1 year. In addition to the predictors of futility mentioned above, lower diffusing capacity of the lung for carbon monoxide has been identified as a pulmonary-specific predictor of futility. ${ }^{50}$

\section{Chronic Kidney Disease}

CKD is a predictor of both 30-day and 1-year mortality in a severitydependent manner (every $10-\mathrm{ml} / \mathrm{min} / 1.73 \mathrm{~m}^{2}$ reduction in baseline estimated glomerular filtration rate increases mortality by $4.4 \%$ ). ${ }^{51}$ Patients on dialysis have an approximately twofold increase in mortality compared with non-dialysis patients. ${ }^{52}$ It also increases the risk of bleeding and stroke among higher-risk patients. ${ }^{53}$ Despite this increased risk, TAVI is a better option than medical treatment, with lower mortality rates (at a mean of 1.9 years, $\mathrm{HR}$ of mortality with medical management compared with TAVI 3.95; 95\% Cl [2.59-6.02]) and potential stabilisation of renal function. ${ }^{54} \mathrm{CKD}$ has been identified as an independent predictor of lack of improvement in functional status, in a severity-dependent manner, mainly due to associated comorbidities, such as anaemia and sarcopenia. ${ }^{46}$

\section{Malignancy}

This heterogenous group of pathologies with varying prognosis based on type, extent and treatment is common in the elderly - one study revealed a $5.4 \%$ prevalence of active cancer and $13.8 \%$ of a prior history of cancer among TAVI patients. ${ }^{55}$ The majority of cancers are prognostically important, and among TAVI patients have been shown to account for $7 \%$ of deaths at 30 days, and between 2 and $8.6 \%$ of deaths at 1 year. ${ }^{3,56,57}$ There is heterogeneity in the literature regarding outcomes in patients with cancer. At 1 year post-TAVI, mortality was higher (37.4 versus 20.8\%; $p<0.001)$ and improvement in functional class was lower among patients with active cancer compared with those without cancer. ${ }^{55}$ Another study demonstrated that active cancer does not affect TAVI procedural success and complications, and that at a median on 272 days, mortality was similar between the cancer and non-cancer group $(p=0.42)$. However, the presence of metastatic cancer was an independent predictor of mortality (HR 4.73, 95\% Cl [1.12-29.0]; $p=0.035) .{ }^{58}$ However, selection bias and confounding factors, such as anaemia and sarcopenia, which tend to coexist with cancer, were not accounted for in both studies. Incidental masses among elderly patients can be found in one in five patients who undergo pre-TAVI CT, with solitary lung nodules being the most common finding. As an entity, incidental masses do not affect outcomes, and the majority are benign. However, among patients with a prior history of cancer where it is more likely to represent malignancy, incidental masses are associated with increased 1-year mortality (OR 4.02; 95\% Cl [1.5-10.7]; $\mathrm{p}=0.006) .{ }^{59}$ Incidental masses may result in further investigations for a patient, providing an opportunity for commencing treatment if appropriate.

For patients in this complex disease group, a tailored approach for each individual is required; with consideration of whether TAVI can facilitate further oncological treatments, such as surgery, and an evaluation by a multidisciplinary team involving an oncologist.

\section{Frailty and Related Conditions Affecting TAVI Outcomes}

Frailty is a state of decreased functional and physiological reserve, and is often caused by the accumulation of health deficits. Understanding frailty helps predict outcomes, stratify risk, and identify patient-specific targets and outcomes. It can also identify patients who may benefit from frailtyspecific interventions. Trials assessing the effectiveness of interventions on frailty among TAVI patients are still awaited; however, these interventions have proved to be beneficial in other populations (NCT03107897 and NCT0352245). Physical, nutritional, and cognitive interventions can improve frailty scores and status at 12 months. ${ }^{60}$ Intensive exercise leads to greater improvements in disability and physical functioning compared with light exercise. ${ }^{61}$ Nutritional supplementation in older patients demonstrated an improvement in quality of life and physical functioning. ${ }^{62}$

The assessment of frailty has generated enormous interest within the TAVI community, with the development of several scoring systems. 
Figure 1: Decision-making Algorithm for Determining Benefit Versus Futility of Transcatheter Aortic Valve Implantation

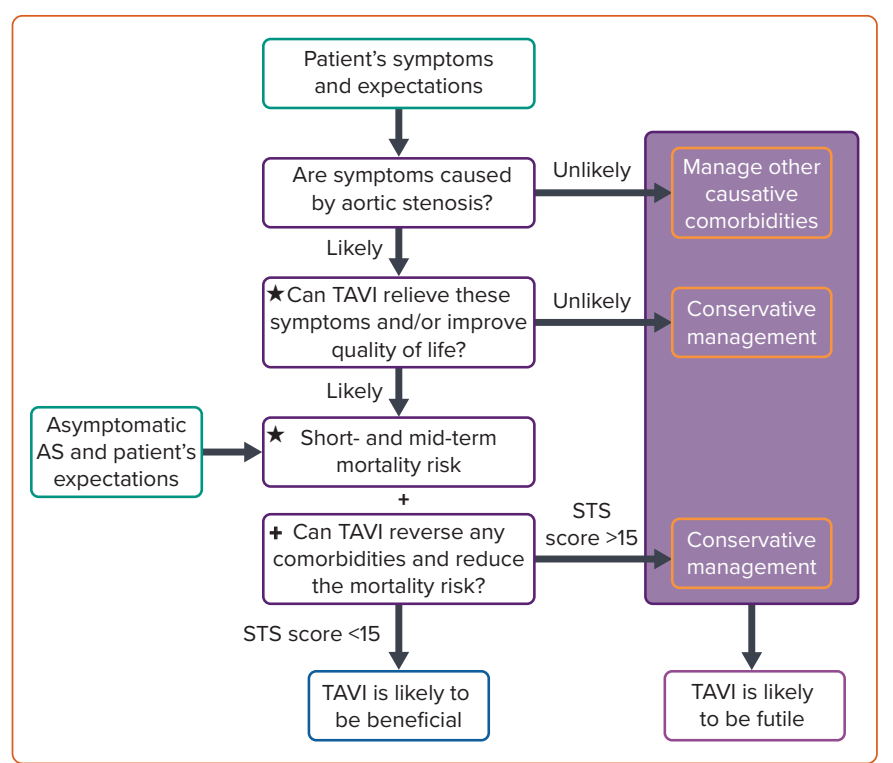

This algorithm should be employed as part of a shared decision-making process that involves the patient. Among asymptomatic patients, the goal of transcatheter aortic valve implantation is largely to reduce mortality risk associated with aortic stenosis and any associated comorbidities. Consequently, the upper section is less relevant. To determine the risk of futility, the relevant sections marked $\star$ and + should be used in conjunction with Figure 2 and Figure 3, respectively. Dichotomising choices and predicting outcomes can be challenging, but based on the data presented above, a reasonable decision can be established. AS = aortic stenosis; STS = Society of Thoracic Surgeons; TAVI = transcatheter aortic valve implantation .

Consequently, the reported prevalence of frailty varies between $6 \%$ and $90 \% .{ }^{63,64}$ Determining which score to use, balancing a comprehensive frailty assessment with a busy clinical workload and determining what to do once frailty has been recognised are challenging. Below, we provide a summary of the main domains of frailty with validated thresholds for futility. Regardless of how frailty is assessed, it is associated with a poor prognosis. Two meta-analyses demonstrated that frailty is an independent predictor of mortality at $\leq 30$ days (HR 2.35; 95\% Cl [1.78-3.09]), >30 day (HR 1.63; 95\% Cl [1.34-1.97]) and at 1 year (HR 2.16, 95\% Cl [1.57-3.00]). ${ }^{65,66}$ Frailty also predicts functional decline post-TAVI (OR 1.82; 95\% CI [1.14-2.91]). ${ }^{67}$

\section{Physical Capacity}

Mobility is a significant contributor to frailty and is often used to approximate its presence. Patients with AS and low physical capacity, determined by either a 6MWT and Timed Up and Go test have a poorer prognosis than those with higher capacities. ${ }^{49,68}$ A 6MWT $<170$ m was identified as the optimum cut-off to predict futility at 6 months among patients with COPD undergoing TAVI (area under the receiver operating characteristic curve 0.67$).{ }^{49}$ One study showed that for every $10 \mathrm{~m}$ walked during a $6 \mathrm{MWT}$, the risk of a poor outcome reduced by $3 \%{ }^{69}$

Patients with Timed Up and Go test times between 10 and 20 seconds have a greater than fivefold increase in mortality at 1 year, compared with patients with a Timed Up and Go test time $<10$ seconds ${ }^{68}$ However, defining specific cut-off points to determine futility using any of these continuous variables is clinically useful, but will misclassify some patients and, therefore, should be used judiciously. Additionally, if a patient's mobility is limited by AS, those with lower values stand to gain the most functional benefit from TAVI. ${ }^{70}$ The key to determining futility is to identify physical limitations caused by non-AS related pathologies, which will not improve with TAVI.

\section{Cognitive Impairment}

Cognitive impairment is under-recognised and a significant contributor to frailty. ${ }^{71}$ Patients with cognitive impairment at baseline (Mini Mental State Examination score $<27$ ) have more than a threefold increased risk of functional decline or mortality at 1-year post-TAVI. ${ }^{72}$ Another study showed that for every point gained on the Mini-Mental Test score, the OR of a poor outcome was 0.94 (95\% Cl [0.90-0.97]; $p=0.001){ }^{71}$

\section{Sarcopenia and Nutrition}

Sarcopenia is a state of low muscle mass, strength and function, and is present in one-third of elderly patients. ${ }^{73}$ Psoas muscle area and volume act as surrogate markers of sarcopenia, and are calculated using preTAVI CT scans. Sarcopenia (psoas muscle area: men $<20.3 \mathrm{~cm}^{2}$ and women $<11.8 \mathrm{~cm}^{2}$ ) has been shown to predict mortality and worsening disability at 1 year. ${ }^{74,75}$ Up to $42 \%$ of patients undergoing TAVI are either at risk of malnourishment or are malnourished. These patients have more comorbidities and a lower BMI. ${ }^{76}$ Lower BMI $\left(<18.5 \mathrm{~kg} / \mathrm{m}^{2}\right)$ at baseline is associated with increased mortality at 1 year rather than at 30 days, whereas, paradoxically, obese and overweight patients tend to have a survival advantage at 1 year. ${ }^{77}$ Functional outcomes among malnourished TAVI patients are unknown.

\section{Outcomes in Specific Populations}

\section{Acute Decompensated Aortic Stenosis}

Acute decompensated AS (ADAS) is defined by debilitating symptoms related to AS (syncope, angina with minimal exertion or at rest and/or dyspnoea at rest). The condition frequently warrants hospitalisation and urgent valve replacement. Although TAVI has been performed safely in these patients, outcomes are worse than patients without decompensation; at 1 year post-TAVI, mortality is between 15.3 and $29.1 \%{ }^{78-80}$ Traditional markers of futility described above predict mortality in ADAS: AF, oxygen-dependent lung disease, low body surface area (a marker of sarcopenia/malnutrition), previous cardiac surgery and poor renal function. ${ }^{80}$ However, there is a large degree of overlap in baseline characteristics between ADAS and non-ADAS patients, making it challenging to differentiate and, therefore, predict futility.

Among patients presenting with acute decompensation is a subgroup with cardiogenic shock. Data on TAVI within this subgroup are limited to small case series. Device success is reportedly high (94\%), However, Valve Academic Research Consortium-2-defined early safety endpoints were reached in $35 \%$ of patients, with 30 -day mortality of $12-24 \%{ }^{81,82}$ At 1 year, mortality was reported at $26 \%$ and related to non-cardiovascular causes in the majority of patients. However, among survivors, TAVI did improve symptoms; $91 \%$ were New York Heat Association class I or class II. ${ }^{81}$ For patients with ADAS, non-randomised data suggest that TAVI is a better therapeutic option than balloon aortic valvuloplasty. ${ }^{80,82}$

\section{Patient Evaluation}

By following a systematic approach, as suggested in Figure 1, using available evidence where present and clinical judgment where absent, a reasonable management decision can be made. Once the severity of AS is established, the next step involves symptom assessment to establish causality and explore a patient's expectations. The third step involves evaluation of a patient's comorbidities, their impact on mortality, symptoms, and quality of life with and without TAVI. Figure 2 identifies specific cut-offs for factors within four key domains that are associated with futility in TAVI. Many factors affect outcomes in a severity-dependent manner, therefore, while specific cut-offs are clinically useful, some patients will be misclassified and, therefore, should be used judiciously. 
Figure 2: Factors Associated With an Increased Risk of Futility in Transcatheter Aortic Valve Implantation

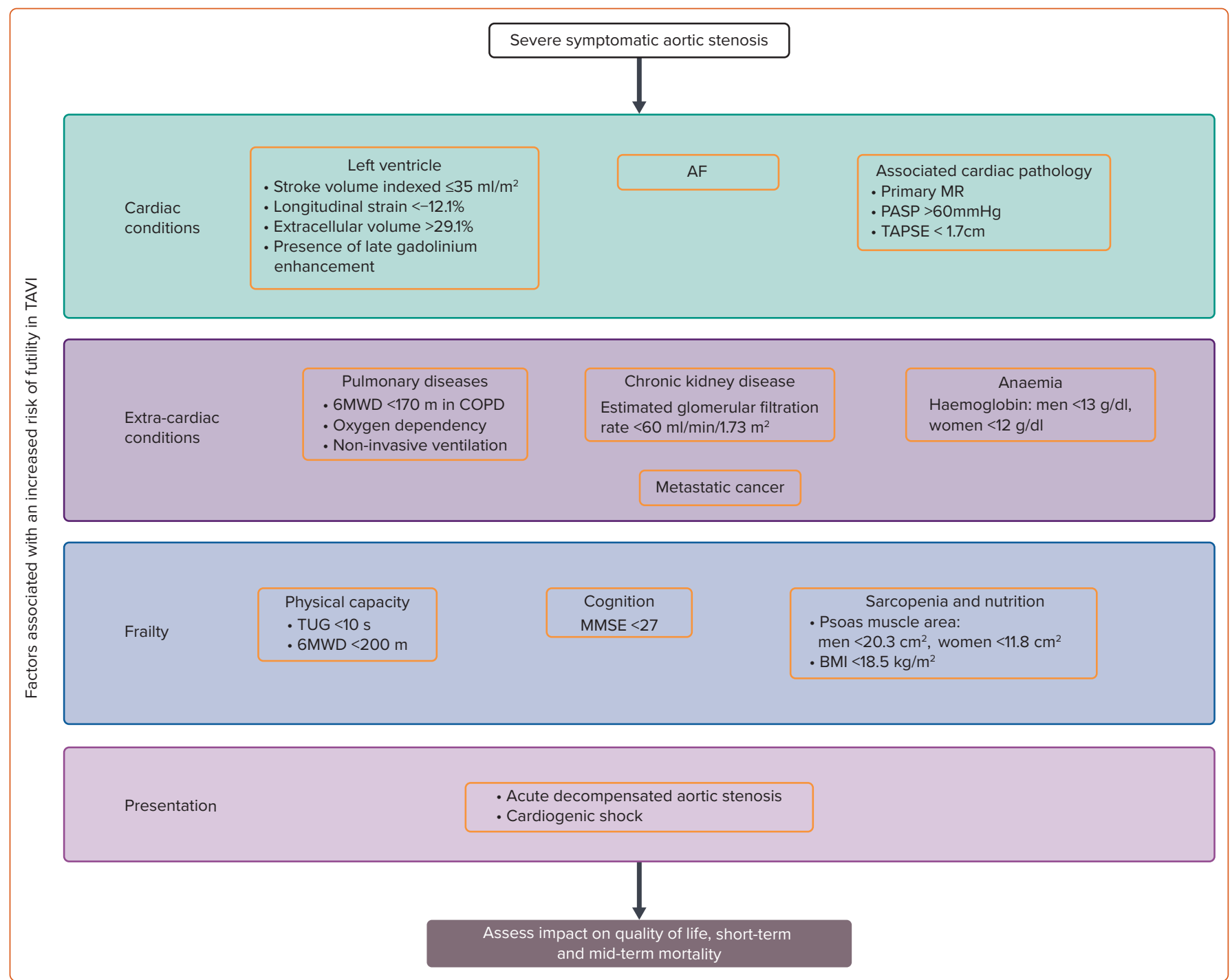

This figure summarises the four key domains and their most common comorbidities that need to be evaluated in the high-/prohibitive-risk, patient. Additionally, for each comorbidity, specific cut-offs have been identified, above or below which futility in transcatheter aortic valve implantation increases. These cut-offs, while clinically useful, should be used judiciously, as most comorbidities demonstrate a severity-dependent impact on outcomes and the cut-offs will misclassify some patients. 6MWT = 6-minute walk test; COPD = chronic obstructive pulmonary disease; MMSE = Mini-Mental State Examination; $M R=$ mitral regurgitation; PASP = pulmonary artery systolic pressure; TAPSE = tricuspid annular plane systolic excursion; TAVI = transcatheter aortic valve implantation; TUG = Timed Up and Go test.

The final step that lends support to the decision-making process is whether TAVI can reverse existing comorbidities to improve outcomes. Figure 3 identifies comorbidities that tend to improve with TAVI. However, improvement in each is dependent on several other factors discussed above. Shared decision-making within a multidisciplinary team and with the patient is a pivotal part of this entire process.

\section{Evaluation of Aortic Stenosis}

Defining the severity of AS is important to justify the risk-benefit balance associated with TAVI; the higher the severity of AS, the greater the benefit of TAVI.

Severe AS is straightforward to define when echocardiographic markers are concordant (peak velocity $\geq 4 \mathrm{~m} / \mathrm{s}$, mean gradient $\geq 40 \mathrm{mmHg}$ and aortic valve area $\leq 1 \mathrm{~cm}^{2}$ ). However, these markers can often be discordant if transvalvular flow is reduced $\left(\leq 35 \mathrm{ml} / \mathrm{m}^{2}\right)$. A detailed review of diagnostic challenges and solutions for low-gradient AS can be found elsewhere. ${ }^{83,84}$ However, two investigations are worth mentioning here. To differentiate between severe AS and pseudo-severe AS, low-dose dobutamine stress
Figure 3: Comorbidities That Can Improve With Transcatheter Aortic Valve Implantation

Comorbidities that can be reversed by TAVI

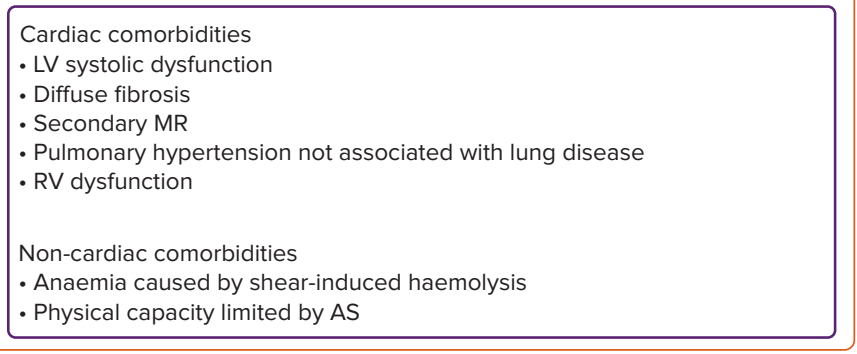

These comorbidities are caused by aortic stenosis and, therefore, can improve with transcatheter aortic valve implantation. However, improvement is dependent on multiple factors. AS = aortic stenosis; $L V=$ left ventricular; $M R=$ mitral regurgitation; $R V=$ right ventricular; $T A V I=$ transcatheter aortic valve implantation.

echocardiography can be helpful. By iatrogenically increasing the flow to $>35 \mathrm{ml} / \mathrm{m}^{2}$, valve haemodynamics can be recalculated at normal flow. If, however, flow cannot be increased sufficiently, the projected aortic valve 
Figure 4: Screening for Frailty

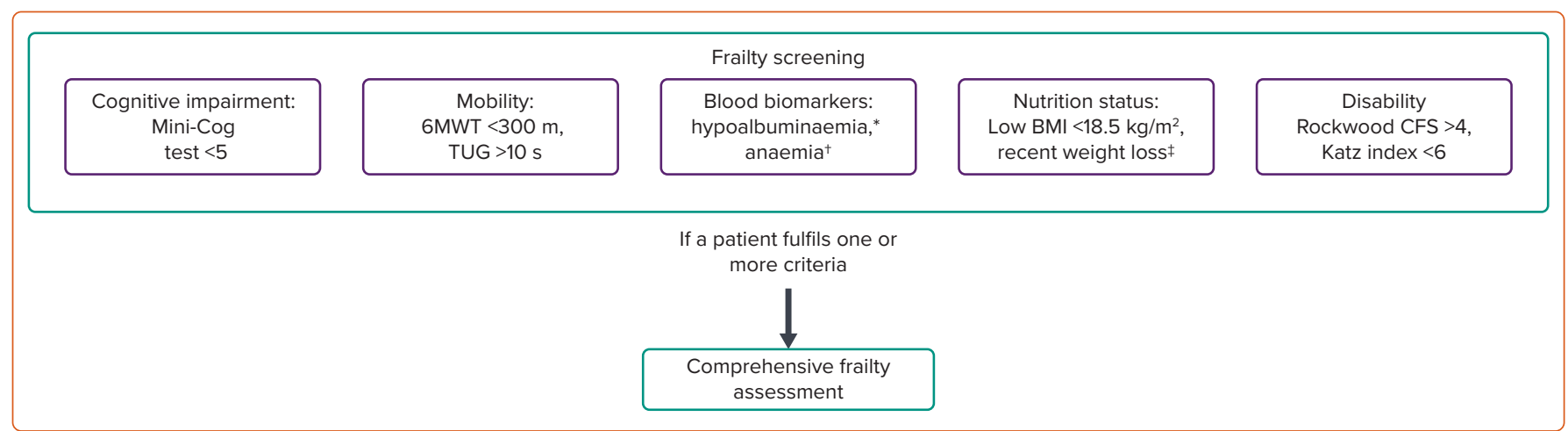

If a patient meets any of these frailty criteria, a comprehensive frailty assessment is recommended. Each assessment has examples of assessments that are simple, quick to perform and routinely used among transcatheter aortic valve implantation patients. *Defined as serum albumin $<3.5 \mathrm{~g} / \mathrm{dl}$; ${ }^{*}$ defined as haemoglobin in men $<13 \mathrm{~g} / \mathrm{dl}$ and in women $<12 \mathrm{~g} / \mathrm{dl}$; $¥$ defined as $>5 \%$ loss in weight over the past 6-12 months. 6MWT = 6-minute walk test; CFS = clinical frailty score; TUG = Timed Up and Go test.

area can be calculated, as described by Blais et al..$^{85}$ Dobutamine stress echocardiography can also provide a measure of contractile reserve (increase in stroke volume by $20 \%$ ). While the presence of contractile reserve is prognostically important in patients undergoing surgical aortic valve replacement, it does not influence outcomes among TAVI patients. ${ }^{86,87}$ Furthermore, the aortic valve calcium score using CT can be beneficial to identify severe AS with established sex-specific cut-offs. ${ }^{88}$ Among elderly, high-risk patients, this is a useful tool; however, in younger patients with bicuspid AS, valve calcification plays less of a role in the pathobiology of $\mathrm{AS}$, and the CT valve calcium score may underestimate the severity of $A S^{89}$

\section{Symptom Evaluation}

Identifying a patient's symptoms and assessing the contribution made by AS is key. Multimorbidity makes attributing symptoms to a particular disease challenging; for example, distinguishing dyspnoea from severe AS versus COPD. If dyspnoea worsens with a simultaneous increase in AS severity and little change in lung function, it is likely that AS is the driving cause. Appreciating a patient's expectations and whether these can be met with TAVI is important. Using the example above, even with successful TAVI, COPD cannot be cured, and a degree of dyspnoea is likely to remain. It is important that the patient understands this.

Patients who have the least to gain from TAVI in terms of symptom benefit and improvements in QoL are those with mild or no symptoms, alternative causes contributing to their symptoms and phenotypic changes (e.g. certain features of frailty) that cannot be reversed with TAVI.

\section{Risk Assessment for High-risk Patients \\ Scoring Systems}

Several frailty parameters and risk scores can be inaccurate, exclude important facets of frailty or require extensive assessments, discouraging their use in the clinical arena. ${ }^{72,90,91}$ Therefore, we propose a simple screening tool to identify frail patients (Figure 4) who would benefit from a more thorough assessment, preferably by a geriatrician. ${ }^{60,62}$ The cutoffs chosen for each domain have demonstrated prognostic or diagnostic importance. $^{68,92-99}$ Included in this screening tool are several factors discussed above. In addition, assessing disability and independence using validated tools, such as the Rockwood Clinical Frailty Score and the Katz index, although semi-quantitative tools, can provide quick and important prognostic data for TAVI patients. ${ }^{66,99,100}$ Interventions to improve frailty and their impact on outcomes are ongoing, limiting the role of comprehensive frailty assessment to risk stratification rather than therapeutic interventions (NCT03107897 and NCT0352245). ${ }^{101,102}$
Although risk stratification using TAVI-specific tools provides a similar or better estimation of mortality compared with traditional surgical risk scores, further refinement is required.103,104 Table 1 summarises the predictors used in several TAVI-specific risk scores and their corresponding C-statistics. The Society of Thoracic Surgeons (STS)/ American College of Cardiology Transcatheter Valve Therapy TAVI score demonstrated an area under the receiver operating characteristic curve of 0.64 in determining 30-day mortality with better discrimination of mortality compared with STS-Predicted Risk of Mortality score for highrisk patients. ${ }^{105}$ Compared with surgical risk scores (Euroscore 2 and STS), the French Aortic National CoreValve and Edwards 2 (FRANCE 2) score had a lower, albeit non-significant $\mathrm{C}$-statistic (0.67 versus 0.53 ; $p=0.26)^{106}$

However, most scores do not predict functional or symptomatic improvements, which for many patients are equally if not more important. Newer tools are taking into consideration both functional/symptomatic outcomes and mortality. One model, predicting the composite of a poor QoL, decrease in QoL and mortality at 1 year, demonstrated moderate discriminatory ability (C-statistic 0.66). Using this model, among patients in a validation cohort judged to be at very high risk $(>70 \%$ risk of the composite endpoint), 73\% met the composite endpoint - demonstrating good predictive ability among this subpopulation. ${ }^{71}$

The Essential Frailty Toolset has been shown to be one of the strongest predictors of mortality at 30 days (OR 3.29; 95\% Cl [1.73-6.26]) and 1 year (OR 3.72; 95\% Cl [2.54-5.45]), as well as worsening disability at 1 year (OR 2.13; 95\% Cl [1.57-2.87]), compared with other scoring systems..$^{90}$ The addition of the Essential Frailty Toolset to STS-PROM shows promise with a C-statistic of 0.83 . If classified as severely frail using the Essential Frailty Toolset (5/5), patients had a $80 \%$ risk of mortality or disability at 1 year. ${ }^{90,107}$ The combination of these two scoring systems could prove to be a reliable tool to determine futility, and requires prospective studies to validate it.

Decisions based on any scoring system need to be made around a patientcentred approach. Patients at very high-risk (STS $>15 \%$ ) do not have a survival benefit compared with conservative treatment. ${ }^{108}$ These newer risk stratification tools need to be validated in different populations, and will need to constantly evolve as TAVI evolves and novel predictors of futility are identified. Future studies are required to address whether frailty can be improved by treating particular factors, such as malnutrition, and whether this can improve TAVI outcomes. 
Table 1: Transcatheter Aortic Valve Implantation-specific Risk Scores from the Original Developmental and Validation Studies

\begin{tabular}{|c|c|c|c|}
\hline TAVI Risk Score & Endpoint & Predictive Factors & C-statistics \\
\hline FRANCE $2^{110}$ & 30-day or in-hospital mortality & $\begin{array}{l}\text { Age } \geq 90 \text { years, } \mathrm{BMI}<18.5 \text { and }<30 \mathrm{~kg} / \mathrm{m}^{2} \text {, New York Heart } \\
\text { Association class IV, pulmonary hypertension, critical } \\
\text { haemodynamic state, } \geq 2 \text { pulmonary oedemas during the past } \\
\text { year, respiratory insufficiency, dialysis and transapical or other } \\
\text { (transaortic and transcarotid) approaches }\end{array}$ & $\begin{array}{l}\text { Development cohort: } 0.67 \\
\text { Validation cohort: } 0.59\end{array}$ \\
\hline $\mathrm{STS} / \mathrm{TVT}^{111}$ & In-hospital mortality & $\begin{array}{l}\text { Age, estimated glomerular filtration rate, haemodialysis, New York } \\
\text { Heart Association functional class IV, severe chronic lung disease, } \\
\text { nonfemoral access site and procedural acuity categories }\end{array}$ & $\begin{array}{l}\text { Development cohort: } 0.67 \\
\text { Validation cohort: } 0.66\end{array}$ \\
\hline PARTNER $^{69}$ & $\begin{array}{l}\text { 6-month mortality, } K C C Q \text { score }<45 \text { or } \\
\geq 10 \text {-point decrease in KCCQ-OS score }\end{array}$ & $\begin{array}{l}\text { Sex, diabetes, major arrhythmia, serum creatinine, mean arterial } \\
\text { pressure, BMI, oxygen dependant lung disease, mean aortic valve } \\
\text { gradient, Mini-Mental State Examination, 6-minute walk test }\end{array}$ & $\begin{array}{l}\text { Development cohort: } 0.66 \\
\text { Validation cohort: } 0.64\end{array}$ \\
\hline CoreValve $^{112}$ & 1-year mortality & $\begin{array}{l}\text { Home oxygen use, albumin levels }<3.3 \mathrm{~g} / \mathrm{dl} \text {, falls in the past } \\
6 \text { months, STS-PROM score }>7 \% \text { and severe }(\geq 5) \text { Charlson } \\
\text { comorbidity score }\end{array}$ & $\begin{array}{l}\text { Development cohort: } 0.83 \\
\text { Validation cohort: } 0.79\end{array}$ \\
\hline $\begin{array}{l}\text { GAVS II }{ }^{113} \\
\text { (Both surgical and transcatheter } \\
\text { aortic valve replacements were } \\
\text { included) }\end{array}$ & In-hospital mortality & $\begin{array}{l}\text { Sex, age, BMI, New York Heart Association functional class IV, } \\
\text { Canadian cardiovascular score } 3 / 4 \text {, cardiogenic shock }<48 \mathrm{~h} \\
\text { ago, cardiopulmonary resuscitation within } 48 \mathrm{~h} \text {, absence of } \\
\text { pulmonary hypertension, sinus rhythm, American Society of } \\
\text { Anaesthesiologists physical status, coronary artery disease, } \\
\text { LVEF <30\%, peripheral vascular disease, infective endocarditis/ } \\
\text { septic condition, diabetes, haemodialysis, mechanical circulatory } \\
\text { support, redo surgery }\end{array}$ & Validation cohort: 0.74 \\
\hline UK TAVI ${ }^{114}$ & 30-day mortality & $\begin{array}{l}\text { Age, sex, critical preoperative status, BMI, extracardiac } \\
\text { arteriopathy, estimated glomerular filtration rate, non- } \\
\text { transfemoral TAVI, pulmonary hypertension, prior balloon aortic } \\
\text { valvuloplasty, pulmonary disease, sinus rhythm, non-elective } \\
\text { procedure, Katz index, poor mobility }\end{array}$ & $\begin{array}{l}\text { Development cohort: } 0.70 \\
\text { Validation cohort: } 0.66\end{array}$ \\
\hline
\end{tabular}

KCCQ-OS = Kansas City Cardiomyopathy Questionnaire Overall Summary; LVEF = left ventricular ejection fraction; TAVI = transcatheter aortic valve implantation.

\section{Role of the Multidisciplinary Team}

The multidisciplinary team has become the cornerstone for making complex management recommendations and is advocated by international guidelines. ${ }^{91,109}$ It is particularly helpful, where equipoise exists regarding the benefit/futility of TAVI. In the multimorbid, frail patient, a geriatrician is invaluable to guide this process. If TAVI is not recommended by the multidisciplinary team, it is important to sensitively convey this to the patient and their relatives. A discussion should be had regarding the patient's thoughts, concerns and expectations, and the rationale for the recommendation. This discussion can then form the basis of the final decision. If a clinical decision has been made to avoid TAVI because of probable futility, palliative care should be involved to alleviate symptoms, personalise care, provide psychological support and ensure good lines of communication for the patient.

\section{Conclusion}

The more comorbidities a patient has, the lower the chances of an improvement in physical and psychological quality of life, and the higher the mortality rate. Additionally, the severity of these comorbidities is important, with higher severity pertaining a higher risk of futility. Futility should be considered, especially in patients whose health is affected primarily by comorbidities other than AS. It is important to consider certain comorbidities that can reverse post-TAVI (e.g. functional MR), despite conferring excess risk. Quantifying the contribution of specific comorbidities to a patient's symptoms can facilitate better prediction of symptomatic improvement and allow patient expectations from TAVI to be managed. Therefore, both patients and clinicians need to be clear about the potential improvements that TAVI can provide.

Although our understanding of comorbidities and their impact on TAVI outcomes has improved, there is still a need to refine our prediction tools, and better understand the impact of TAVI on QoL and function, such that this rapidly growing technology is targeted towards those patients who are likely to gain the most benefit and avoided amongst those where it will be futile. $\square$

\section{Clinical Perspective}

- Futility in transcatheter aortic valve implantation (TAVI) is common and should be avoided. Up to half of high-risk patients undergoing TAVI do not gain any improvement in quality of life (QoL), symptoms or survival at 1 year.

- The number and severity of comorbidities increase the risk of futility.

- However, certain comorbidities can be reversed with TAVI, thus improving outcomes; for example, functional mitral regurgitation and anaemia caused by intravascular haemolysis.

- Screening and a comprehensive assessment of comorbidities and frailty can lead to better risk prediction and reduce futility.

- Further research is required to identify predictors of a lack of improvement in QoL and function. 
1. Arnold SV, Afilalo J, Spertus JA, et al. Prediction of poor outcome after transcatheter aortic valve replacement. J Am Coll Cardiol 2016;68:1868-77. https://doi.org/10.1016/j. jacc.2016.07.762; PMID: 27765189.

2. Reynolds MR, Magnuson EA, Wang K, et al. Health-related quality of life after transcatheter or surgical aortic valve replacement in high-risk patients with severe aortic stenosis. J Am Coll Cardiol 2012;60:548-58. https://doi. org/10.1016/j.jacc.2012.03.075; PMID: 22818074

3. Wendler O, Schymik G, Treede H, et al. SOURCE 3: 1-year outcomes post-transcatheter aortic valve implantation using the latest generation of the balloon-expandable transcatheter heart valve. Eur Heart J 2017;38:2717-26. https://doi.org/10.1093/eurheartj/ehx294; PMID: 28605423.

4. Baumgartner H, Falk V, Bax JJ, et al. 2017 ESC/EACTS guidelines for the management of valvular heart disease. Eur Heart J 2017;38:2739-91. https://doi.org/10.1093/ eurheartj/ehx391; PMID: 28886619.

5. Biviano AB, Nazif T, Dizon J, et al. Atrial fibrillation is associated with increased mortality in patients undergoing transcatheter aortic valve replacement: Insights from the Placement of Aortic Transcatheter Valve (PARTNER) trial. Circ Cardiovasc Interv 2016;9:e002766. https://doi.org/10.1161/ CIRCINTERVENTIONS.115.002766; PMID: 26733582

6. Stortecky S, Buellesfeld L. Wenaweser P, et al. Atria fibrillation and aortic stenosis: Impact on clinical outcomes among patients undergoing transcatheter aortic valve implantation. Circ Cardiovasc Interv 2013;6:77-84. https://doi. org/10.1161/CIRCINTERVENTIONS.112.000124; PMID: 23386662

7. Sannino A, Gargiulo G, Schiattarella GG, et al. A metaanalysis of the impact of pre-existing and new-onset atrial fibrillation on clinical outcomes in patients undergoing transcatheter aortic valve implantation. Eurolntervention 2016;12:e1047-56. https://doi.org/10.4244/EIJY15M11_12; PMID: 26610809

8. Tarantini G, Mojoli M, Windecker S, et al. Prevalence and impact of atrial fibrillation in patients with severe aortic stenosis undergoing transcatheter aortic valve replacement: an analysis from the SOURCE XT Prospective Multicenter Registry. JACC Cardiovasc Interv 2016;9:937-46. https://do org/10.1016/j.jcin.2016.01.037; PMID: 27085579.

9. Tarantini G, Mojoli M, Urena M, Vahanian A. Atrial fibrillation in patients undergoing transcatheter aortic valve implantation: epidemiology, timing, predictors, and outcome. Eur Heart J 2017;38:1285-93. https://doi. org/10.1093/eurheartj/ehw456; PMID: 27744287.

10. Amat-Santos J, Rodes-Cabau. J, Urena M et al. Incidence, predictive factors, and prognostic value of new-onset atria fibrillation following transcatheter aortic valve implantation. J Am Coll Cardiol 2012;59:178-88. https://doi.org/10.1016/j. jacc. 2011.09.061; PMID: 22177537.

11. Urena M, Webb JG, Eltchaninoff $\mathrm{H}$, et al. Late cardiac death in patients undergoing transcatheter aortic valve replacement: Incidence and predictors of advanced heart failure and sudden cardiac death. J Am Coll Cardiol 2015;65:437-48. https://doi.org/10.1016/j.jacc.2014.11.027; PMID: 25660921

12. Manger N, Stachel G, Woitek F, et al. Predictors of mortality and symptomatic outcome of patients with low-flow severe aortic stenosis undergoing transcatheter aortic valve replacement. J Am Heart Assoc 2019;7:e007977. https://doi. org/10.1161/JAHA.117.007977; PMID: 29654191

13. Annabi MS, Côté N, Dahou A, et al. Comparison of Early Surgical or Transcatheter Aortic Valve Replacement versus conservative management in low-flow, low-gradient aortic stenosis using inverse probability of treatment weighting: results from the TOPAS prospective observational cohort study. J Am Heart Assoc 2020;9:e017870. https://doi. org/10.1161/JAHA.120.017870; PMID: 33289422

14. Herrmann HC, Pibarot P, Hueter I, et al. Predictors of mortality and outcomes of therapy in low-flow severe aortic stenosis: a Placement of Aortic Transcatheter Valves (PARTNER) trial analysis. Circulation 2013;127:2316-26 https://doi.org/10.1161/CIRCULATIONAHA.112.001290; PMID: 23661722.

15. Elmariah S, Palacios IF, McAndrew T, et al. Outcomes of transcatheter and surgical aortic valve replacement in highrisk patients with aortic stenosis and left ventricula dysfunction: results from the Placement of Aortic Transcatheter Valves (PARTNER) trial (cohort A). Circ Cardiovasc Interv 2013;6:604-14. https://doi.org/10.1161 CIRCINTERVENTIONS.113.000650; PMID: 24221391.

16. Kearney LG, Lu K, Ord M, et al. Global longitudinal strain is a strong independent predictor of all-cause mortality in patients with aortic stenosis. Eur Heart J Cardiovasc Imaging 2012;13:827-33. https://doi.org/10.1093/ehjci/jes115; PMID: 22736713.

17. Kusunose K, Goodman A, Parikh R, et al. Incremental prognostic value of left ventricular global longitudinal strain in patients with aortic stenosis and preserved ejection fraction. Circ Cardiovasc Imaging 2014;7:938-45. https://doi. org/10.1161/CIRCIMAGING.114.002041; PMID: 25320287

18. Dweck MR, Joshi S, Murigu T, et al. Midwall fibrosis is an independent predictor of mortality in patients with aortic stenosis. J Am Coll Cardiol 2011;58:1271-9. https://doi. org/10.1016/j.jacc.2011.03.064; PMID: 21903062.

19. Dobson LE, Musa TA, Uddin A, et al. Acute reverse remodelling after transcatheter aortic valve implantation: a link between myocardial fibrosis and left ventricular mass regression. Can J Cardiol 2016;32:1411-8. https://doi. org/10.1016/j.cjca.2016.04.009; PMID: 27523272

20. Everett RJ, Treibel TA, Fukui M, et al. Extracellular myocardial volume in patients with aortic stenosis. J Am Coll Cardio/ 2020;75:304-16. https://doi.org/10.1016/j. jacc 201911.032: PMID· 31976869

21. Scully PR, Patel KP, Treibel TA, et al. Prevalence and outcome of dual aortic stenosis and cardiac amyloid pathology in patients referred for transcatheter aortic valve implantation. Eur Heart J 2020;41:2759-67. https://doi. org/10.1093/eurheartj/ehaa170; PMID: 32267922.

22. Castaño A, Narotsky DL, Hamid N, et al. Unveiling transthyretin cardiac amyloidosis and its predictors among elderly patients with severe aortic stenosis undergoing transcatheter aortic valve replacement. Eur Heart 2017;38:2879-87. https://doi.org/10.1093/eurheartj/ehx350; PMID: 29019612

23. Sannino A, Losi MA, Schiattarella GG, et al. Meta-analysis of mortality outcomes and mitral regurgitation evolution in 4,839 patients having transcatheter aortic valve implantation for severe aortic stenosis. Am J Cardiol 2015;114:875-82. https://doi.org/10.1016//. amjcard.2014.06.022; PMID: 25092192

24. O'Sullivan CJ, Stortecky S, Bütikofer A, et al. Impact of mitral regurgitation on clinical outcomes of patients with lowejection fraction, low-gradient severe aortic stenosis undergoing transcatheter aortic valve implantation. Circ Cardiovasc Interv 2015;8:e001895. https://doi.org/10.1161/ CIRCINTERVENTIONS.114.001895; PMID: 25657315.

25. Muratori M, Fusini L, Tamborini G, et al. Mitral valve regurgitation in patients undergoing TAVI: impact of severity and etiology on clinical outcome. Int J Cardiol 2020;299:228-34. https://doi.org/10.1016/j. ijcard 2019.07.060: PMID: 3135315

26. Bedogni F, Latib A, Marco F De, et al. Interplay between mitral regurgitation and transcatheter aortic valve replacement with the Corevalve revalving system: a multicenter registry. Circulation 2013:128:2145-53. https:// doi.org/10.1161/CIRCULATIONAHA.113.001822; PMID: 24088530

27. Barbanti M, Webb JG, Hahn RT, et al. Impact of preoperative moderate/severe mitral regurgitation on 2-year outcome after transcatheter and surgical aortic valve replacement. Circulation 2013;128:2776-84. https://doi.org/10.1161 CIRCULATIONAHA.113.003885; PMID: 24152861.

28. Khawaja MZ, Williams R, Hung J, et al. Impact of preprocedural mitral regurgitation upon mortality after transcatheter aortic valve implantation (TAVI) for severe aortic stenosis. Heart 2014;100:1799-803. https://doi. org/10.1136/heartjnl-2014-305775; PMID: 25155800

29. Gerosa G, Bianco R, Renier V, et al. Impact of preoperative mitral valve regurgitation on outcomes after transcatheter aortic valve implantation. Eur J Cardio Thoracic Surg 2012;41:1271-7. https://doi.org/10.1093/ejcts/ezr236 PMID: 22219481.

30. Witberg G, Codner P, Landes U, et al. Transcatheter treatment of residual significant mitral regurgitation following TAVR: a multicenter registry. JACC Cardiovasc Inter 2020;13:2782-91. https://doi.org/10.1016/j.jcin.2020.07.014 PMID: 33303117.

31. Testa L, Rubbio AP, Casenghi M, et al. Transcatheter mitral valve replacement in the transcatheter aortic valve replacement era. J Am Heart Assoc 2019;8:e013352. https:// doi.org/10.1161/JAHA.119.013352; PMID: 31694451

32. Grayburn PA, Packer M, Sannino A, Stone GW. Disproportionate secondary mitral regurgitation: myths, misconceptions and clinical implications. Heart 2021;107:528-34. https://doi.org/10.1136/ heartjnl-2020-316992; PMID: 33234674

33. Tang M, Liu X, Lin C, et al. Meta-analysis of outcomes and evolution of pulmonary hypertension before and afte transcatheter aortic valve implantation. Am J Cardiol 2017;119:91-9. https://doi.org/10.1016/j.amjcard.2016.09.015 PMID: 27788934

34. Sinning JM, Hammerstingl C, Chin D, et al. Decrease of pulmonary hypertension impacts on prognosis after transcatheter aortic valve replacement. Eurolntervention 2014;9:1042-9. https://doi.org/10.4244/EIJV919A177; PMID: 24168931

35. O'Sullivan CJ, Wenaweser P, Ceylan O, et al. Effect of pulmonary hypertension hemodynamic presentation on clinical outcomes in patients with severe symptomatic aortic valve stenosis undergoing transcatheter aortic valve mplantation insights from the new proposed pulmonary hypertension classification. Circ Cardiovasc Interv 2015;8:e002358. https://doi.org/10.1161/ CIRCINTERVENTIONS.114.002358: PMID: 26156149.

36. Alushi B, Beckhoff F, Leistner D, et al. Pulmonary hypertension in patients with severe aortic stenosis: prognostic impact after transcatheter aortic valve replacement: pulmonary hypertension in patients undergoing TAVR. JACC Cardiovasc Imaging 2018;12:591-601. https://doi.org/10.1016/j.jcmg.2018.02.015; PMID: 29680341.

37. Masri A, Abdelkarim I, Sharbaugh MS, et al. Outcomes of persistent pulmonary hypertension following transcathete aortic valve replacement. Heart 2018:104:821-7. https://doi. org/10.1136/heartjnl-2017-311978; PMID: 28970276

38. Luçon A, Oger E, Bedossa M, et al. Prognostic implications of pulmonary hypertension in patients with severe aortic stenosis undergoing transcatheter aortic valve implantation study from the FRANCE 2 registry. Circ Cardiovasc Interv 2014;7:240-7. https://doi.org/10.1161/ CIRCINTERVENTIONS.113.000482; PMID: 24569597.

39. Asami M, Stortecky S, Praz F, et al. Prognostic value of right ventricular dysfunction on clinical outcomes after transcatheter aortic valve replacement. JACC CardiovasC Imaging 2019;12:577-87. https://doi.org/10.1016/j. jcmg.2017.12.015; PMID: 29454762

40. Bohbot Y, Guignant P, Rusinaru D, et al. Impact of right ventricular systolic dysfunction on outcome in aortic stenosis. Circ Cardiovasc Imaging 2020;13:e009802. https:// doi.org/10.1161/CIRCIMAGING.119.009802; PMID: 31959010

41. Nuis RJ, Sinning JM, Rodés-Cabau J, et al. Prevalence, factors associated with, and prognostic effects of preoperative anemia on short-and long-term mortality in patients undergoing transcatheter aortic valve implantation. Circ Cardiovasc Interv 2013;6:625-34. https://doi.org/10.1093/ eurheartj/eht310.P5426; PMID: 24280965.

42. Mieghem NM Van, Nuis RJ, Tzikas A, et al. Prevalence and prognostic implications of baseline anaemia in patients undergoing transcatheter aortic valve implantation. Eurolntervention 2011;7:184-91. https://doi.org/10.4244 EIJV7I2A32; PMID: 21646060

43. Nagao K, Taniguchi T, Morimoto T, et al. Anemia in Patients with severe aortic stenosis. Sci Rep 2019;9:1924. https://doi. org/10.1038/s41598-018-36066-z; PMID: 30760807.

44. Rheude T, Pellegrini C, Michel J, et al. Prognostic impact of anemia and iron-deficiency anemia in a contemporary cohort of patients undergoing transcatheter aortic valve implantation. Int J Cardio/ 2017; 244:93-9. https://doi. org/10.1016/j.ijcard.2017.06.024; PMID: 28645804.

45. Godino C, Lauretta L, Pavon AG, et al. Heyde's syndrome incidence and outcome in patients undergoing transcatheter aortic valve implantation. J Am Coll Cardio 2013;61:687-9. https://doi.org/10.1016/j.jacc.2012.10.041 PMID: 23391203

46. Bagur R, Rodés-Cabau J, Dumont É, et al. Exercise capacity in patients with severe symptomatic aortic stenosis before and six months after transcatheter aortic valve implantation. Am J Cardio/ 2011;108:258-64. https://doi.org/10.1016/j. amjcard.2011.03.031; PMID: 21545988.

47. Liao YB, He ZX, Zhao ZG, et al. The relationship between chronic obstructive pulmonary disease and transcatheter aortic valve implantation - a systematic review and metaanalysis. Catheter Cardiovasc Interv 2016;87:570-8. https:// doi.org/10.1002/ccd.26443; PMID: 26856312

48. Gotzmann M, Knoop H, Ewers A, et al. Impact of lung diseases on morbidity and mortality after transcatheter aortic valve implantation: Insights from spirometry and body plethysmography. Am Heart J 2015;170:837-42.e1. https:// doi.org/10.1016/i.ahj.2015.07.011; PMID: 26386809.

49. Mok M, Nombela-Franco L, Dumont E, et al. Chronic obstructive pulmonary disease in patients undergoing transcatheter aortic valve implantation: Insights on clinical outcomes, prognostic markers, and functional status changes. JACC Cardiovasc Interv 2013:6:1072-84. https://doi. org/10.1016/j.jcin.2013.06.008; PMID: 24156967.

50. Crestanello JA, Popma JJ, Adams DH, et al. Long-term health benefit of transcatheter aortic valve replacement in patients with chronic lung disease. JACC Cardiovasc Interv 2017:10:2283-93.https://doi.org/10.1016/j.jcin.2017.07.025 PMID: 29102579

51. Ferro CJ, Chue CD, Belder MA De, et al. Impact of renal function on survival after transcatheter aortic valve implantation (TAVI): an analysis of the UK TAVI registry. Heart 2015;101:546-52. https://doi.org/10.1136/ heartjnl-2014-307041; PMID: 25582121.

52. Schymik G, Bramlage P, Herzberger V, et al. Impact of dialysis on the prognosis of patients undergoing transcatheter aortic valve implantation. Am J Cardiol 
2019;123:315-22. https://doi.org/10.1016/j. amjcard 2018.10.008: PMID: 30424871

53. Makki N, Lilly SM. Advanced chronic kidney disease: Relationship to outcomes post-TAVR, a meta-analysis. Clin Cardio/ 2018;41:1091-6. https://doi.org/10.1002/clc.22993; PMID: 29896847.

54. Steinmetz T, Witberg G, Chagnac A, et al. Transcatheter aortic valve implantation versus conservative treatment in chronic kidney disease patients. Eurolntervention 2018;14:e503-10. https://doi.org/10.4244/EIJ-D-18-00058: PMID: 29688177.

55. Mangner N, Woitek FJ, Haussig S, et al. Impact of active cancer disease on the outcome of patients undergoing transcatheter aortic valve replacement. J Interv Cardiol 2018;31:188-96. https://doi.org/10.1111/joic.12458; PMID: 29166702.

56. Xiong TY, Liao YB, Zhao ZG, et al. Causes of death following transcatheter aortic valve replacement: A systematic review and meta-analysis. J Am Heart Assoc 2015;4:e002096. https://doi.org/10.1161/JAHA.115.002096; PMID: 26391132.

57. Leon MB, Smith CR, Mack M, et al. Transcatheter aorticvalve implantation for aortic stenosis in patients who cannot undergo surgery. N Engl J Med 2010;363:1597-607. https:// doi.org/10.1056/NEJMoa1008232; PMID: 20961243.

58. Watanabe $\mathrm{Y}$, Kozuma K, Hioki H, et al. Comparison of results of transcatheter aortic valve implantation in patients with versus without active cancer. Am J Cardiol 2016;118:572-7. https://doi.org/10.1016/j.amjcard.2016.05.052; PMID: 27324159.

59. Ghotra AS, Monlezun DJ, Boone D, et al. Outcomes of patients undergoing transcatheter aortic valve implantation with incidentally discovered masses on computed tomography. Am J Cardiol 2020;132:114-8. https://doi. org/10.1016/i.amjcard.2020.07.003; PMID: 32798041

60. Ng TP, Feng L, Nyunt MSZ, et al. Nutritional, physical, cognitive, and combination interventions and frailty reversa among older adults: a randomized controlled trial. Am J Med 2015;128:1225-36.e1. https://doi.org/10.1016/j. amjmed 2015.06.017: PMID: 26159634

61. Binder EF, Schechtman KB, Ehsani AA, et al. Effects of exercise training on frailty in community-dwelling olde adults: results of a randomized, controlled trial. J Am Geriatr Soc 2002;50:1921-8. https://doi.org/10.1046/j.1532-5415. 2002.50601.x; PMID: 12473001

62. Gariballa S, Forster S. Dietary supplementation and quality of life of older patients: a randomized, double-blind, placebo-controlled trial. J Am Geriatr Soc 2007;55:2030-4. https://doi.org/10.1111/j.1532-5415.2007.01435.x; PMID: 17944893.

63. Petronio AS, Giannini C. Frailty in patients undergoing TAVI: how can we measure it? Eurolntervention 2019;15:652-5. https://doi.org/10.4244/EIJV15I8A120; PMID: 31625913.

64. Li Z, Dawson E, Moodie J, et al. Measurement and prognosis of frail patients undergoing transcatheter aortic valve implantation: a systematic review and meta-analysis. BMJ 2021;11:e040459. https://doi.org/10.1136/ bmjopen-2020-040459; PMID: 33664067

65. Anand A, Harley C, Visvanathan A, et al. The relationship between preoperative frailty and outcomes following transcatheter aortic valve implantation: a systematic review and meta-analysis. Eur Hear J Qual Care Clin Outcomes 2017;3:123-32. https://doi.org/10.1093/ehjqcco/qcw030; PMID: 28927173.

66. Mourik MS van, Velu JF, Lanting VR, et al. Preoperative frailty parameters as predictors for outcomes after transcatheter aortic valve implantation: a systematic review and meta-analysis. Neth Heart J 2020;28:280-92. https:// doi.org/10.1007/s12471-020-01379-0; PMID: 32189208.

67. Gregorevic KJ, Hubbard RE, Lim WK, Katz B. The clinical frailty scale predicts functional decline and mortality when used by junior medical staff: a prospective cohort study. BMC Geriatrics 2016;16:117. https://doi.org/10.1186/s12877-016 0292-4; PMID: 27250650

68. Eichler S, Salzwedel A, Harnath A, et al. Nutrition and mobility predict all-cause mortality in patients 12 months after transcatheter aortic valve implantation. Clin Res Cardio 2018;107:304-11. https://doi.org/10.1007/s00392-017-1183-1; PMID: 29164390.

69. Arnold SV, Reynolds MR, Lei Y, et al. Predictors of poor outcomes after transcatheter aortic valve replacement results from the PARTNER (Placement of Aortic Transcathete Valve) trial. Circulation 2014;129:2682-90. https://doi. org/10.1161/CIRCULATIONAHA.113.007477; PMID: 24958751.

70. Green P, Cohen DJ, Généreux P, et al. Relation between sixminute walk test performance and outcomes after transcatheter aortic valve implantation (from the PARTNER trial). Am J Cardiol 2013;112:700-6. https://doi.org/10.1016/j. amjcard.2013.04.046; PMID: 23725996

71. Graham JE, Rockwood K, Beattie BL, et al. Prevalence and severity of cognitive impairment with and without dementia in an elderly population. Lancet 1997;349:1793-6. https://doi. org/10.1016/S0140-6736(97)01007-6; PMID: 9269213.

72. Schoenenberger AW, Stortecky S, Neumann S, et al. Predictors of functional decline in elderly patients undergoing transcatheter aortic valve implantation (TAVI). Eur Heart J 2013;34:684-92. https://doi.org/10.1093/ eurheartj/ehs304; PMID: 23008508.

73. Brown JC, Harhay MO, Harhay MN. Sarcopenia and mortality among a population-based sample of communitydwelling older adults. J Cachexia Sarcopenia Muscle 2016;7:290-8. https://doi.org/10.1002/jcsm.12073; PMID: 27239410.

74. Kleczynski P, Tokarek T, Dziewierz A, et al. Usefulness of psoas muscle area and volume and frailty scoring to predict outcomes after transcatheter aortic valve implantation. Am J Cardio/ 2018;39:910-1. https://doi.org/10.1016/j. amjcard.2018.03.020; PMID: 29703441.

75. Mamane S, Mullie L, Lok Ok Choo W, et al. Sarcopenia in older adults undergoing transcatheter aortic valve replacement. J Am Coll Cardio/ 2019;74:3178-80. https://doi. org/10.1016/j.jacc.2019.10.030; PMID: 31856975.

76. Wernio E, Jagielak D, Dardzińska JA, et al. Analysis of outcomes of the nutritional status in patients qualified for aortic valve replacement in comparison to healthy elderly. Nutrients 2018:10:304. https://doi.org/10.3390/nu10030304; PMID: 29510548

77. Yamamoto M, Mouillet G, Oguri A, et al. Effect of body mass index on 30- and 365-day complication and survival rates of transcatheter aortic valve implantation (from the FRench Aortic National CoreValve and Edwards 2 [FRANCE 2] registry). Am J Cardiol 2013;112:1932-7. https://doi. org/10.1016/j.amjcard.2013.08.022; PMID: 24063832.

78. Patel K, Broyd C, Chehab O, et al. Transcatheter aortic valve implantation in acute decompensated aortic stenosis. Catheter Cardiovasc Interv 2020;96:e348-54. https://doi. org/10.1002/ccd.28581; PMID: 31696656

79. Kolte D, Khera S, Vemulapalli S, et al. Outcomes following urgent/emergent transcatheter aortic valve replacement: insights from the STS/ACC TVT Registry. JACC CardiovasC Interv 2018;11:1175-85. https://doi.org/10.1016/j. jcin.2018.03.002; PMID: 29929641.

80. Ali N, Patel P, Wahab A, et al. A cohort study examining urgent and emergency treatment for decompensated severe aortic stenosis. J Cardiovasc Med 2021;22:126-32. https://doi.org/10.2459/JCM.0000000000001112; PMID: 32941330.

81. Fraccaro C, Campante Teles $\mathrm{R}$, Tchétché $\mathrm{D}$, et al. Transcatheter aortic valve implantation (TAVI) in cardiogenic shock: TAVI-shock registry results. Catheter Cardiovasc Intery 2020;96:1128-35. https://doi.org/10.1002/ccd.29112; PMID: 32627924

82. Bongiovanni D, Kühl C, Bleiziffer S, et al. Emergency treatment of decompensated aortic stenosis. Heart 2018;104:23-9. https://doi.org/10.1136/heartjnl-2016-311037; PMID: 28566471

83. Clavel MA, Magne J, Pibarot P. Low-gradient aortic stenosis. Eur Heart J 2016;37:2645-57. https://doi.org/10.1093/ eurheartj/ehw096; PMID: 27190103.

84. Dahou A, Pibarot P. Low-flow low-gradient aortic stenosis: when is it severe? American College of Cardiology Expert Analysis, 15 January 2015. https://www.acc.org/latest-incardiology/articles/2015/12/08/09/53/low-flow-low-gradientaortic-stenosis-when-is-it-severe (accessed 23 November 2021).

85. Blais C, Burwash IG, Mundigler G, et al. Projected valve area at normal flow rate improves the assessment of stenosis severity in patients with low-flow, low-gradient aortic stenosis. Circulation 2006;113:711-21. https://doi.org/10.1161/ CIRCULATIONAHA.105.557678; PMID: 16461844.

86. Tribouilloy C, Lévy F, Rusinaru D, et al. Outcome after aortic valve replacement for low-flow/low-gradient aortic stenosis without contractile reserve on dobutamine stress echocardiography. J Am Coll Cardio/ 2009;53:1865-73. https://doi.org/10.1016/j.jacc.2009.02.026; PMID: 19442886

87. Ribeiro HB, Lerakis S, Gilard M, et al. Transcatheter aortic valve replacement in patients with low-flow, low-gradient aortic stenosis: the TOPAS-TAVI registry. J Am Coll Cardiol 2018;71:1297-308. https://doi.org/10.1016/j.jacc.2018.01.054; PMID: 29566812

88. Clavel MA, Messika-Zeitoun D, Pibarot P, et al. The complex nature of discordant severe calcified aortic valve disease grading: new insights from combined Doppler echocardiographic and computed tomographic study. J Am Coll Cardiol 2013;62:2329-38. https://doi.org/10.1016/j. jacc.2013.08.1621; PMID: 24076528

89. Cartlidge TRG, Pawade TA, Dweck MR. Aortic stenosis and CT calcium scoring: is it for everyone? Heart 2017;103:8-9. https://doi.org/10.1136/heartjnl-2016-310297; PMID: 27647167.

90. Afilalo J, Lauck S, Kim DH, et al. Frailty in older adults undergoing aortic valve replacement: the FRAILTY-AVR study. J Am Coll Cardiol 2017;70:689-700. https://doi. org/101016/j.jacc 2017.06.024: PMID: 28693934

91. Baumgartner H, Falk V, Bax JJ, et al. 2017 ESC/EACTS guidelines for the management of valvular heart disease. Eur Heart J 2017;38:2739-86. https://doi.org/10.1093/ eurhearti/ehx391; PMID: 28886619.

92. Poirier P, Bastien M, Auclair A, et al. The physiological burden of the 6 -minute walk test compared with cardiopulmonary exercise stress test in patients with severe aortic stenosis. CJC Open 2021;3:769-77. https://doi. org/10.1016/j.cjco.2021.02.003; PMID: 34169256.

93. Arenaza DP de, Flather M, Lees B, et al. Abstract 2337. Role of preoperative 6 minute walk test in the assessment and prognosis of patients with severe aortic stenosis undergoing aortic valve replacement. Circulation 2006;114(Suppl 18):II_478.

94. Bastien M, Bagur RH, Rodes-Cabau J, et al. Abstract P423. Six minutes walk test in patients with severe aortic stenosis: a maximal exercise testing procedure? Circulation 2013;127 (Suppl 12):AP423. https://doi.org/10.1161/circ.127.suppl_12. AP423.

95. Arenaza DP de, Pepper J, Lees B, et al. Preoperative 6 -minute walk test adds prognostic information to Euroscore in patients undergoing aortic valve replacement. Heart 2010;96:113-7. https://doi.org/10.1136/hrt.2008.161174; PMID: 19561363.

96. Podsiadlo D, Richardson S. The timed "up \& go": a test of basic functional mobility for frail elderly persons. J Am Geriatr Soc 1991;39:142-8. https://doi.org/10.1111/j.1532-5415.1991. tb01616.x; PMID: 1991946.

97. Yokomizo JE, Simon SS, Campos Bottino CM de. Cognitive screening for dementia in primary care: a systematic review. Int Psychogeriatrics 2014;26:1783-804. https://doi.org/10.1017/ S1041610214001082; PMID: 25023857.

98. Khan MM, Lanctôt KL, Fremes SE, et al. The value of screening for cognition, depression, and frailty in patients referred for TAVI. Clin Interv Aging 2019;14:841-8. https://doi. org/10.2147/CIA.S201615; PMID: 31190770.

99. Shimura T, Yamamoto M, Kano S, et al. Impact of the clinica frailty scale on outcomes after transcatheter aortic valve replacement. Circulation 2017;135:2013-24. https://doi. org/10.1161/CIRCULATIONAHA.116.025630; PMID: 28302751.

100. Afilalo J. The clinical frailty scale: upgrade your eyeball test. Circulation 2017;135:2025-7. https://doi.org/10.1161/ CIRCULATIONAHA.116.025958; PMID: 28302750.

101. Skaar E, Eide LSP, Norekvål TM, et al. A novel geriatric assessment frailty score predicts 2-year mortality after transcatheter aortic valve implantation. Eur Hear J Qual Care Clin Outcomes 2018:5:153-60. https://doi.org/10.1093/ ehjqcco/qcy044; PMID: 30256921.

102. Ungar A, Mannarino G, van der Velde N, et al. Comprehensive geriatric assessment in patients undergoing transcatheter aortic valve implantation - results from the CGA-TAVI multicentre registry. BMC Cardiovasc Disord 2018;18:1. https://doi.org/10.1186/s12872-017-0740-x; PMID: 29301486

103. Kötting J, Schiller W, Beckmann A, et al. German Aortic Valve Score: a new scoring system for prediction of mortality related to aortic valve procedures in adults. Eur $J$ Cardiothoracic Surg 2013:43:971-7. https://doi.org/10.1093/ ejcts/ezt114; PMID: 23477927

104. Capodanno D, Barbanti M, Tamburino C, et al. A simple risk tool (the OBSERVANT score) for prediction of 30-day mortality after transcatheter aortic valve replacement. Am J Cardiol 2014:113:1851-8. https://doi.org/10.1016/j. amjcard.2014.03.014; PMID: 24837264.

105. Reiff C Gurevich S, Bertog S, et al Validation of STS/ACC TVT-TAVR score in veterans undergoing transcatheter aortic valve replacement. J Invasive Cardiol 2018;30:447-51. PMID: 30218556

06. Carmo J, Teles RC, Madeira S, et al. Comparison of multiparametric risk scores for predicting early mortality after transcatheter aortic valve implantation. Rev Port Cardiol 2018;37:585-90. https://doi.org/10.1016/j.repc.2017.09.028; PMID: 30008314

107. Mack MJ, Stoler R. Intervention for Aortic Stenosis: The Measurement of Frailty Matters. J Am Coll Cardio 2017;70:701-3. https://doi.org/10.1016/j.jacc.2017.06.035; PMID: 28774375

108. Makkar RR, Fontana GP, Jilaihawi H, et al. Transcatheter aortic-valve replacement for inoperable severe aortic stenosis. N Engl J Med 2012;366:1696-704. https://doi. org/10.1056/NEJMoa1202277; PMID: 22443478.

109. Khanji MY, Ricci F, Galusko V, et al. Management of aortic stenosis: a systematic review of clinical practice guidelines and recommendations. Eur Heart J Qual Care Clin Outcomes 2021;7:340-53. https://doi.org/10.1093/ehjqcco/qcab016; PMID: 33751049

110. lung B, Laouénan C, Himbert D, et al. Predictive factors of early mortality after transcatheter aortic valve implantation: 
individual risk assessment using a simple score. Heart 2014;100:1016-23. https://doi.org/10.1136 heartjin-2013-305314; PMID: 24740804

111. Edwards FH, Cohen DJ, O'Brien SM, et al. Development and validation of a risk prediction model for in-hospital mortality after transcatheter aortic valve replacement. JAMA Cardiol 2016;1:46-52. https://doi.org/10.1001/jamacardio.2015.0326;
PMID: 27437653.

112. Hermiller JB, Yakubov SJ, Reardon MJ, et al. Predicting early and late mortality after transcatheter aortic valve replacement. J Am Coll Cardiol 2016;68:343-52. https://doi. org/10.1016/j.jacc.2016.04.057; PMID: 27443429

113. Schiller W, Barnewold L, Kazmaier T, et al. The German Aortic Valve Score II. Eur J Cardiothoracic Surg 2017;52:881-7. https://doi.org/10.1093/ejcts/ezx282; PMID: 28950361 114. Martin GP, Sperrin M, Ludman PF, et al. Novel United Kingdom prognostic model for 30-day mortality following transcatheter aortic valve implantation. Heart 2018;104:1109 16. https://doi.org/10.1136/heartjnl-2017-312489,

PMID: 29217636 